\title{
Adverse Reaction
}

National Cancer Institute

\section{Source}

National Cancer Institute. Adverse Reaction. NCI Thesaurus. Code C41332.

Any noxious and unintended response(s) to a medical product or procedure, for which a causal relationship with this product or procedure is at least a reasonable possibility i.e., the relationship cannot be ruled out. 